\title{
Timing of Antiretroviral Therapy for HIV in the Setting of TB Treatment
}

\author{
Damani A. Piggott ${ }^{1}$ and Petros C. Karakousis ${ }^{1,2}$ \\ ${ }^{1}$ Division of Infectious Diseases, Department of Medicine, Johns Hopkins University School of Medicine, 1550 Orleans Street, \\ Rm 110, Baltimore, MD 21231, USA \\ ${ }^{2}$ Department of International Health, Johns Hopkins Bloomberg School of Public Health, Baltimore, MD 21205, USA
}

Correspondence should be addressed to Petros C. Karakousis, petros@jhmi.edu

Received 27 July 2010; Revised 6 October 2010; Accepted 20 October 2010

Academic Editor: Estee Torok

Copyright (C) 2011 D. A. Piggott and P. C. Karakousis. This is an open access article distributed under the Creative Commons Attribution License, which permits unrestricted use, distribution, and reproduction in any medium, provided the original work is properly cited.

The convergent human immunodeficiency virus (HIV) and tuberculosis (TB) pandemics continue to collectively exact significant morbidity and mortality worldwide. Highly active antiretroviral therapy (HAART) has been a critical component in combating the scourge of these two conditions as both a preemptive and therapeutic modality. However, concomitant administration of antiretroviral and antituberculous therapies poses significant challenges, including cumulative drug toxicities, drug-drug interactions, high pill burden, and the immune reconstitution inflammatory syndrome (IRIS), thus complicating the management of coinfected individuals. This paper will review data from recent studies regarding the optimal timing of HAART initiation relative to TB treatment, with the ultimate goal of improving coinfection-related morbidity and mortality while mitigating toxicity resulting from concurrent treatment of both infections.

\section{Convergence of HIV/TB Pandemics}

There are approximately 33 million HIV-infected persons worldwide, of whom approximately 2 million are children [1]. An estimated 2 million deaths have been attributed annually to HIV/AIDS, with approximately 250,000 pediatric deaths. One third of the world's population is infected with Mycobacterium tuberculosis. In 2007, there were approximately 9.3 million incident cases of TB [2], with an estimated 1 million of these occurring in children [3].

The HIV pandemic has fueled a rise in both TB incidence and mortality, with an approximately $40 \%$ increase in incident TB cases compared to 20 years ago [4]. In the USA, one quarter of all TB cases occur in HIV-infected persons [5] and worldwide an estimated 1.37 million (14.8\%) TB cases occur in HIV-positive persons, resulting in 456,000 TBrelated deaths in this population [2]. HIV/TB coinfection is particularly prevalent in populations with limited resources. Thus, the prevalence of HIV infection among patients with TB ranges from $50 \%$ to $80 \%$ in sub-Saharan Africa, as compared to $2-15 \%$ in other parts of the world.
HIV/TB coinfected persons have been shown to have a higher mortality rate than those without either infection alone, regardless of CD4 count [6]. TB accounts for $26 \%$ of AIDS-related deaths worldwide and 29\% of TB-related mortality has been attributed to HIV infection [2].

An estimated 500,000 cases of multidrug-resistant (MDR) TB (defined as resistance to the first line agents rifampin and isoniazid) occur annually [7], with a similar prevalence among HIV-infected persons as for HIVuninfected persons, as MDR-TB strains do not appear to be more transmissible or pathogenic in the setting of HIV/AIDS. However, relative to the general population, factors such as congregation, delayed diagnosis, and inadequate initial treatment, contribute to periodic outbreaks of MDRTB in HIV-infected populations [8]. Moreover, outbreaks of extremely drug-resistant (XDR) TB (defined as MDR-TB plus resistance to any fluoroquinolone and at least one of the three injectable second-line drugs capreomycin, kanamycin, and amikacin) have been reported with increasing frequency, with particularly deadly consequences for HIV-coinfected individuals [9]. 


\section{Pathogenesis of HIV/TB Coinfection}

The fate of M. tuberculosis infection in the human host is dependent in large part on host innate and adaptive immune responses. Initial recognition of the tubercle bacillus depends upon innate immune receptor recognition of conserved pathogen-associated molecular patterns (PAMPs) of $M$. tuberculosis [10-12]. In the appropriate host cellular environment, the adaptive immune system is primed to contain, but usually not eradicate, the infection within necrotic granulomas, leading to latent $\mathrm{TB}$ infection. In particular, CD4 $\mathrm{T}$ cells are critical in the control of $M$. tuberculosis infection, as quantitative and qualitative deficiencies of these effector cells in HIV-infected individuals increase the rates of both primary and reactivation disease. While the lifetime risk of developing active TB is approximately $10 \%$ for immunecompetent persons following initial infection, for persons with HIV coinfection the annual risk can exceed 10\% [13], and the risk of $\mathrm{TB}$ reactivation rises as the $\mathrm{CD} 4$ cell count declines [14-16].

\section{Prevention of Active TB in HIV-Positive Patients}

Treatment of latent TB infection with isoniazid is highly effective in preventing the progression to active disease among HIV-infected persons [17, 18]. A recent meta-analysis of randomized controlled trials revealed a reduction in the incidence of active TB of over 30\% in persons receiving chemoprophylactic treatment compared to those receiving placebo [19].

HAART also has been found to play an important role in preventing the development of active TB in HIVpositive patients, reducing the incidence of $\mathrm{TB}$ by up to $90 \%$ in patients receiving such therapy relative to those not receiving antiretroviral drugs [20-22]. However, despite viral suppression with HAART, the risk of TB remains higher in HIV-infected persons than in HIV-uninfected persons, suggesting incomplete immune restoration in the former group [23].

\section{Potential Challenges in the Treatment of HIV-Associated TB}

The concomitant treatment of HIV and active TB poses significant challenges, particularly relating to the duration and frequency of dosing of anti-TB drugs and the optimal timing of HAART initiation relative to TB treatment, which has important consequences vis-à-vis overlapping drug toxicities and drug-drug interactions between anti-TB drugs and antiretroviral drugs as well as the immune reconstitution inflammatory syndrome (IRIS).

Although current guidelines recommend a 6-month rifamycin-based regimen for treatment of drug-susceptible pulmonary TB regardless of HIV status [24], the results of two randomized trials suggest that relapse rates after such therapy may be higher among HIV-infected persons than among HIV-uninfected persons $[25,26]$. A recent meta-analysis of randomized, controlled trials and cohort studies found that at least 8 months duration of rifamycinbased therapy, daily drug dosing during the initial phase of treatment, and concurrent antiretroviral therapy are associated with improved outcomes in HIV-associated TB [27]. Although intermittent dosing under direct observation is a mainstay of TB treatment regimens in the USA and elsewhere, highly intermittent (once or twice weekly) therapy has been associated with increased relapse rates in HIVinfected persons, often with acquired rifamycin resistance $[28,29]$.

Concurrent treatment of TB and HIV is associated with a higher risk of adverse reactions compared to treatment of either infection alone. In particular, the first-line antituberculous drugs isoniazid, rifampin, and pyrazinamide may each cause hepatotoxicity, which may be compounded by concurrent use of protease inhibitors and nonnucleoside reverse transcriptase inhibitors [30, 31]. Since HIVinfected persons are at increased risk for isoniazid-induced peripheral neuropathy, these patients should take vitamin B6 and avoid antiretroviral drugs with potential peripheral neurotoxicity (e.g., stavudine and didanosine). Additionally, gastrointestinal distress and high pill burden can contribute to reduced tolerability and adherence to a combined TB/HIV therapeutic regimen.

Pharmacokinetic interactions between HIV and TB regimens can have a significant impact on the therapeutic efficacy of each regimen. Potent induction of the cytochrome p450 system by rifampin can lead to subtherapeutic levels of the protease inhibitors accompanied by virological failure. Rifabutin, another rifamycin with less potent induction of the p450 system, may be used together with protease inhibitors, but its dose must be decreased to avoid rifabutinrelated toxicity. However, rifabutin is not readily available in many resource-limited settings [32]. Rifampin also reduces levels of the nonnucleoside reverse transcriptase inhibitors efavirenz and nevirapine. Although these interactions do not appear to have a deleterious effect on virological outcomes with efavirenz-based therapy, increased rates of virological failure have been reported with concomitant nevirapine use $[33,34]$.

Initiation of antiretroviral therapy in HIV/TB-coinfected individuals can also result in an initial paradoxical clinical deterioration known as IRIS. IRIS has been reported in up to $30 \%$ of HIV-infected persons subsequent to HAART initiation [35-37]. Individuals with low initial CD4 counts, who experience a rapid rise in their CD4 cell count or rapid decline in their HIV viral load soon after initiating HAART, are at increased risk for developing IRIS [38-41]. TB-related IRIS may manifest as high fever, worsening pulmonary infiltrates and respiratory compromise, increasing lymphadenopathy, and neurological deterioration with the potential for severe morbidity and mortality [38-48].

Despite the significant challenges posed by concomitant treatment of HIV and TB infections, delaying HAART until after the completion of TB treatment in coinfected persons may carry its own attendant risks. As early antiretroviral therapy in HIV-infected persons has been shown to reduce the risk of AIDS progression and death [49], concerns have 
been raised that even brief delays in HAART initiation can lead to substantial increases in mortality [50]. Therefore, there has been significant interest recently in determining the optimal timing of HAART initiation relative to TB treatment in the setting of HIV-associated TB.

\section{Optimal Timing of Antiretroviral Therapy in HIV/TB-CoInfected Persons}

Leonard et al. studied HIV/TB coinfected individuals, who were followed between 1991 and 1997 at a single center in Atlanta, Georgia [51]. Increased one year survival rates were observed in the 1994 and 1997 patient cohorts compared to the 1991 cohort, suggesting a correlation between increased survival and concurrent antiretroviral and anti-TB therapy, although a direct role for HAART in improved clinical outcomes could not be inferred from this study (see Table 1).

Three studies based in Thailand attempted to elucidate the risks and benefits of concomitant treatment of HIV and TB in coinfected individuals. A retrospective study by Sungkanuparph et al. at a single site in Thailand evaluated 29 adult patients with HIV/TB coinfection, all with CD4 counts less than 200 [52]. Antiretroviral therapy was initiated between 4 and 12 weeks after initiation of antituberculous therapy, based on clinical stability on the TB regimen. A single death in this cohort was attributed to CMV infection, and one case of IRIS was observed. Additional reported adverse events included rash with nevirapine, dizziness with efavirenz, and anemia with d4T. Although this study was limited by the relatively small sample size and lack of a control group, 26 of the 29 patients were able to complete a full course of TB treatment while taking antiretroviral drugs, suggesting the potential tolerability of dual therapy.

Manosuthi et al. subsequently performed a larger retrospective cohort study with approximately 1000 adult HIVinfected persons with active TB diagnosed by clinical symptoms and positive sputum acid-fast smear [53]. A uniform anti-TB regimen was administered with the standard initial 2-month regimen comprising isoniazid, rifampin, pyrazinamide, and ethambutol, followed by 4 months of isoniazid and rifampin. There was some variability in the antiretroviral regimen employed with $80 \%$ of individuals receiving a nevirapine-based regimen, $16 \%$ an efavirenz-based regimen, and the remainder receiving a protease inhibitor-based regimen. Concurrent TB treatment and HAART appeared to confer a significant survival benefit, with a mortality rate of $7.7 \%$ in the group receiving both treatments, compared to $67.7 \%$ in the group receiving TB treatment alone. Although this study was limited by the greater underlying morbidity in the group not receiving HAART, with more advanced TB and higher rates of drug resistance noted in this group, subgroup analysis demonstrated significantly greater survival among patients receiving HAART within 6 months of TB diagnosis as compared to those receiving HAART beyond 6 months of TB diagnosis. However, patients in whom HAART was started within 2 months of TB treatment initiation did not appear to have improved survival relative to those who began receiving HAART 4 months after initiating TB treatment.
A third Thai-based study by Sanguanwongse et al. also attempted to evaluate the role of HAART on survival of HIV/TB-coinfected individuals [54]. This observational cohort study evaluated $626 \mathrm{HIV} / \mathrm{TB}$-coinfected patients receiving HAART together with $\mathrm{TB}$ treatment and 643 HIV/TB-coinfected patients receiving TB treatment alone. A significant decline in mortality was observed in the group receiving concurrent HAART (11\%) compared to the group not receiving HAART (46\%). Although this study was nonrandomized and precise information on the HAART regimen employed for each patient was lacking, it provided further support for the potential benefit of concomitant HAART and TB treatment.

Five recent studies have attempted to address the appropriate timing of initiation of HAART in HIV/TB-coinfected patients. A small retrospective study in Tehran involving 69 individuals with HIV/TB coinfection was divided into 2 groups [55]. One group, treated from 2002 to 2005, received HAART after 8 weeks of TB treatment if the CD4 count was less than 200. The second group, treated from 2005 to 2006, received HAART after 2 weeks of TB treatment if the CD4 count was less than 100 and after 8 weeks if the CD4 count was between 101 and 200. A lower mortality rate and higher rate of TB cure was observed in the latter group suggesting that early initiation of HAART may be beneficial at lower CD4 counts in HIV-associated TB. No difference in adverse events including IRIS and new opportunistic infections was reported between these 2 groups [55].

A partially retrospective, multicenter study in Madrid, Spain compared HAART initiation within 2 months of TB diagnosis to HAART initiation 3 months subsequent to TB diagnosis [56]. No difference in virological or immunological outcomes was observed between these 2 groups, although the early HAART group had lower mean baseline viral loads. However, early HAART initiation (within 2 months) was associated with improved survival [56].

The aforementioned studies were primarily observational and retrospective in nature. The need for prospective randomized controlled trials to address the clinically important question of the optimal timing of HAART initiation relative to antituberculous therapy led to the design of several such trials in recent years [60]. The Starting Antiretroviral Therapy at Three Points in Tuberculosis (SAPIT) trial, an open label, randomized controlled trial conducted in a large clinic in Durban, South Africa [58], enrolled HIVpositive adult patients with a CD4 count $<500$ and AFB smear-positive TB. The TB regimen consisted of a 2-month standard initial phase with rifampin, isoniazid, ethambutol, and pyrazinamide for TB treatment-naïve individuals, with the addition of streptomycin for treatment-experienced individuals, followed by rifampin and isoniazid during the continuation phase. All patients received the same HAART regimen (didanosine, lamivudine, and efavirenz) and counseling regarding medical adherence. There were 3 main arms of this study: a sequential therapy arm in which patients received HAART subsequent to completion of TB treatment, an early integrated therapy arm in which patients received HAART within 4 weeks after the start of TB treatment, and a late integrated therapy arm in which HAART was 
TABLE 1: Studies on initiation of highly active antiretroviral therapy (HAART) in HIV/TB-coinfected individuals.

\begin{tabular}{|c|c|c|c|c|}
\hline Study (author, year) & Study characteristics & $\begin{array}{l}\text { Timing of HAART } \\
\text { relative to TB treatment }\end{array}$ & Outcomes & Adverse events \\
\hline $\begin{array}{l}\text { Leonard et al. } \\
2002[51]\end{array}$ & $\begin{array}{l}\text { - Retrospective cohort } \\
\text { - } 644 \text { adults and children } \\
\text { (60\% pulmonary TB, 25\% } \\
\text { pulmonary and } \\
\text { extrapulmonary TB, 15\% } \\
\text { extrapulmonary TB) } \\
\text { - Single center - Atlanta, GA } \\
\text { - Comparison of } 3 \text { HIV/TB } \\
\text { coinfected cohorts: 1991, } \\
\text { 1994, } 1997\end{array}$ & $\begin{array}{l}\text { HAART at time of } \\
\text { diagnosis versus HAART } \\
\text { post-TB diagnosis - } \\
\text { not defined }\end{array}$ & $\begin{array}{l}\text { Decreased } 1 \text { year } \\
\text { mortality in } 1994 \text { and } \\
1997 \text { cohort compared } \\
\text { to } 1991 \text { cohort }\end{array}$ & N/A \\
\hline $\begin{array}{l}\text { Sungkanuparph } \\
\text { et al. } 2006 \text { [52] }\end{array}$ & $\begin{array}{l}\text { - Retrospective, observational } \\
\text { - } 29 \text { adult patients }(69 \% \\
\text { pulmonary TB, } 31 \% \\
\text { extrapulmonary TB) } \\
\text { - Jan } 2002-\text { Dec } 2002 \\
\text { - Single center-Thailand }\end{array}$ & $\begin{array}{l}\text { Median } 8 \text { weeks (range } \\
4-12 \text { weeks) }\end{array}$ & $\begin{array}{l}\text { Virological suppression } \\
-65 \% \text { at } 24 \text { weeks } \\
-76 \% \text { at } 48 \text { weeks } \\
\text { TB outcomes } \\
-26 / 29 \text { completed } \\
\text { therapy } \\
\text {-No relapse } \\
\text {-No new OI }\end{array}$ & $\begin{array}{l}\text { IRIS-1/29 } \\
\text { Death-1/29 (CMV } \\
\text { encephalitis) } \\
\text { Rash-2/29 (NVP) } \\
\text { EFV switched to NVP 1/29 } \\
\text { (dizziness) } \\
\text { AZT switched to D4T 3/29 } \\
\text { (anemia) }\end{array}$ \\
\hline $\begin{array}{l}\text { Manosuthi et al. } \\
2006[53]\end{array}$ & $\begin{array}{l}\text { - Retrospective cohort } \\
\text { - } 1003 \text { adult patients } \\
\text { - Jan 2000-Dec } 2004 \\
\text { - Single center - Thailand } \\
\text { - Comparison of HAART + to } \\
\text { HAART - group }\end{array}$ & $\begin{array}{l}2 \text { mth versus } 4 \mathrm{mth} \\
\text { versus } \\
6 \mathrm{mth} \text { versus } 9 \mathrm{mth} \\
\text { versus } \\
12 \mathrm{mth} \text { (subgroup } \\
\text { analysis) }\end{array}$ & $\begin{array}{l}\text { Increased survival for } \\
\text { pts. receiving HAART as } \\
\text { compared to no HAART } \\
\text { Increased mortality with } \\
\text { HAART initiation at } \\
>6 \text { mths. }(11.3 \%) \\
\text { compared to }<6 \text { mths } \\
(4.1 \%)(P=.018)\end{array}$ & N/A \\
\hline $\begin{array}{l}\text { Sanguanwongse } \\
\text { et al. } 2008 \text { [54] }\end{array}$ & $\begin{array}{l}\text { - Observational cohort } \\
\text { - } 1269 \text { patients (adult and } \\
\text { pediatric) ( } 54 \% \text { pulmonary } \\
\text { TB, 35\% extrapulmonary TB, } \\
12 \% \text { both) } \\
\text { - Oct } 2004-\text { March } 2006 \\
\text { - Multicenter - Thailand } \\
\text { National Surveillance Network }\end{array}$ & Not defined & $\begin{array}{l}\text { Decreased mortality in } \\
\text { group receiving HAART } \\
\text { (11\%) compared to that } \\
\text { not receiving HAART } \\
(46 \%) \text { (relative risk } 0.24 \text {, } \\
95 \% \text { confidence interval: } \\
0.19 \text { to } 0.30)\end{array}$ & N/A \\
\hline $\begin{array}{l}\text { Tabarsi et al. } \\
2009[55]\end{array}$ & $\begin{array}{l}\text { - Retrospective cohort } \\
\text { - } 69 \text { patients } \\
\text { - 2002-2006 }\end{array}$ & $\begin{array}{l}\text { Group I: HAART after } \\
8 \text { wks if CD4 }<100 \\
\text { Group II: HAART at } \\
2 \text { wks if CD } 4<100 \\
\text { Group I \& II: HAART } \\
\text { after } 8 \text { wk if CD4 } \\
101-200\end{array}$ & $\begin{array}{l}\text { Increased mortality } \\
\text { when HAART deferred } \\
\text { after } 8 \text { weeks if CD } 4 \\
<100 \text { Group I versus } \\
\text { Group II mortality = } \\
27.7 \% \text { versus } 4.5 \% \\
(P=.03)\end{array}$ & $\begin{array}{l}\text { No difference between } \\
\text { groups I and II regarding } \\
\text { Grade } 3 \text { or } 4 \text { events, IRIS, } \\
\text { or new OI }\end{array}$ \\
\hline $\begin{array}{l}\text { Velasco et al. } \\
2009[56]\end{array}$ & $\begin{array}{l}\text { - Mixed retrospective/ } \\
\text { prospective study } \\
\text { - } 313 \text { patients } \\
\text { - 1996-2004 }\end{array}$ & $\begin{array}{l}\text { - Simultaneous: HAART } \\
\text { within } 2 \text { mths of TB } \\
\text { diagnosis } \\
\text { - Nonsimultaneous: } \\
\text { HAART after } 3 \text { mths of } \\
\text { TB diagnosis }\end{array}$ & $\begin{array}{l}\text { - Decreased mortality in } \\
\text { simultaneous group } \\
(9.3 \%) \text { versus } \\
\text { nonsimultaneous group } \\
(19.7 \%)(P=.011) \\
\text { - No difference in viro- } \\
\text { logical/immunological } \\
\text { outcomes }\end{array}$ & N/A \\
\hline $\begin{array}{l}\text { Torok et al. } \\
2009 \text { [57] }\end{array}$ & $\begin{array}{l}\text { - Randomized, double blind, } \\
\text { placebo-controlled trial } \\
\text { - } 253 \text { patients } \\
\text { - Vietnam } \\
\text { - Clinical diagnosis of TB } \\
\text { meningitis }\end{array}$ & $\begin{array}{l}\text { HAART started within } 7 \\
\text { days (immediate arm) or } \\
\text { at } 2 \text { mths (deferred arm) } \\
\text { after initiation of TB } \\
\text { treatment }\end{array}$ & $\begin{array}{l}\text { Mortality: } \\
\text {-Immediate arm: } 76 \\
\text { deaths/127 pts } \\
\text {-Deferred arm: } 70 \\
\text { deaths/126 pts } \\
(\mathrm{HR}=1.16, P=.31)\end{array}$ & $\begin{array}{l}\text { Incidence of grade } 3 \text { or } 4 \\
\text { adverse events first } 2 \text { mths: } \\
\text {-Immediate: } 86 \% \\
\text {-Deferred: } 75 \%(P=.04)\end{array}$ \\
\hline
\end{tabular}


Table 1: Continued.

\begin{tabular}{|c|c|c|c|c|}
\hline Study (author, year) & Study characteristics & $\begin{array}{l}\text { Timing of HAART } \\
\text { relative to TB treatment }\end{array}$ & Outcomes & Adverse events \\
\hline $\begin{array}{l}\text { Abdool Karim } \\
\text { et al. } 2010[58]\end{array}$ & $\begin{array}{l}\text { - Open-label, randomized, } \\
\text { controlled trial } \\
\text { - } 642 \text { patients } \\
\text { - Durban, South Africa } \\
\text { - Only patients with positive } \\
\text { sputum smear for acid-fast } \\
\text { bacilli and CD } 4 \text { count }< \\
500 / \mathrm{mm}^{3} \text { included }\end{array}$ & $\begin{array}{l}\text { HAART started either } \\
\text { during TB treatment (in } \\
\text { two integrated-therapy } \\
\text { groups) or after } \\
\text { completion of TB } \\
\text { treatment (in one } \\
\text { sequential-therapy } \\
\text { group) }\end{array}$ & $\begin{array}{l}\text { Mortality rate per } \\
100 \text { py: } \\
\text {-Integrated arm: } 5.4 \\
\text {-Sequential arm: } 12.1 \\
(P=.003) \text { Virological } \\
\text { suppression } 6 \text { mths after } \\
\text { HAART initiation: } \\
\text {-Integrated arm: } 91.1 \% \\
\text {-Sequential arm: } 86.7 \% \\
(P=.4)\end{array}$ & $\begin{array}{l}\text { Incidence of IRIS: } \\
\text {-Integrated arm: } 12.4 \% \\
\text {-Sequential arm: } \\
3.8 \%(P \leq .001) \\
\text { Grade } 3 \text { or } 4 \text { adverse events: } \\
\text { Integrated arm: } 30 / 100 \text { py } \\
\text { Sequential arm: } 32 / 100 \text { py } \\
(P=.69)\end{array}$ \\
\hline $\begin{array}{l}\text { Blanc et al. } \\
2010 \text { [59] }\end{array}$ & $\begin{array}{l}\text { - Open label randomized, } \\
\text { controlled trial } \\
\text { - } 661 \text { patients } \\
\text { - Cambodia } \\
\text { - Only patients with positive } \\
\text { smear for acid-fast bacilli and } \\
\text { CD } 4 \text { count }<200 / \mathrm{mm}^{3} \\
\text { included }\end{array}$ & $\begin{array}{l}\text { HAART started at } 2 \\
\text { weeks (early arm) or } 8 \\
\text { weeks (late arm) after } \\
\text { initiation of TB } \\
\text { treatment }\end{array}$ & $\begin{array}{l}\text { Mortality rate per } \\
100 \text { py: } \\
\text {-Early arm: } 8.28 \\
\text {-Late arm: } 13.77 \\
(P=.002) \text { Virological } \\
\text { suppression } 50 \text { wks after } \\
\text { HAART initiation: } \\
\text {-Early arm: } 95.6 \% \\
\text {-Late arm: } 95.6 \% \\
(P=.82)\end{array}$ & $\begin{array}{l}\text { Incidence of IRIS per } 100 \\
\text { pm: } \\
\text {-Early arm: } 4.03 \\
\text {-Late arm: } 1.44(P<.0001)\end{array}$ \\
\hline
\end{tabular}

OI: Opportunistic infections IRIS: Immune reconstitution inflammatory syndrome EFV: Efavirenz NVP: Nevirapine pts: Patients HR: Hazard ratio py: Personyears pm: Person-months N/A: Not available.

administered within 4 weeks after completion of the initial phase of treatment. Patients were randomly assigned to one of these 3 groups and the primary outcome was all-cause mortality. The sequential therapy arm was stopped early by the data and safety monitoring committee upon interim analysis of the data. A significant $56 \%$ decline in mortality was observed in the combined integrated arms compared to the sequential arm, with a mortality rate of 5.4 per 100 person-years in the former group as compared to 12.1/100 person-years in the latter group. Similar rates of virological suppression were observed in each of the groups after similar duration of HAART, and no difference was observed in grade 3 and grade 4 events between the groups.

The initial findings of the SAPIT trial provide compelling evidence for the superiority of integrated versus sequential antituberculous and antiretroviral therapy for coinfected individuals. Further elucidation of the precise timing of HAART initiation relative to TB treatment has been provided recently by the Cambodian Early versus Late Introduction of Antiretrovirals (CAMELIA) trial [59]. This study was an open label, prospective, randomized controlled trial enrolling HIV-positive adult patients with a CD4 count $<200 / \mathrm{mm}^{3}$ and AFB smear-positive TB at 5 sites in rural and urban Cambodia. Patients were treated with a 2-month intensive phase TB regimen consisting of rifampin, isoniazid, pyrazinamide, and ethambutol, followed by a 4 month continuation phase regimen of rifampin and isoniazid. Participants were randomized to 2 arms, an early arm in which HAART was introduced 2 weeks subsequent to the initiation of antituberculous therapy and a late arm in which HAART was introduced 8 weeks subsequent to the initiation of antituberculous therapy. Patients in each arm received a HAART regimen consisting primarily of lamivudine, stavudine, and efavirenz. The preliminary report from this study noted a significant $34 \%$ decline in mortality in the early HAART arm compared to the late HAART arm, with a mortality rate of 8.28 per 100 person-years in the early arm as compared to 13.77 per 100 person-years in the late arm. Similar rates of virological suppression were observed in both groups.

The AIDS Clinical Trials Group recently completed a study entitled "A Strategy Study of Immediate Versus Deferred Initiation of Antiretroviral Therapy for HIV Infected Persons Treated for Tuberculosis With CD4 Less Than 200 Cells $/ \mathrm{mm}^{3 "}$ [61]. This study was an open-label, randomized controlled trial conducted between August 2006 and July 2010, which enrolled persons aged $\geq 13$ years old with CD4 count less than 200 cells $/ \mathrm{mm}^{3}$ and confirmed or probable TB. Participants were assigned to early initiation of HAART within 2 weeks after initiating TB treatment, or deferral of HAART until 8 to 12 weeks after initiation of TB treatment. The majority of participants received efavirenz, tenofovir, and emtricitabine and the primary outcome measure was the proportion of participants who have survived without AIDS progression. The analysis of this study is pending.

\section{Conclusions and Future Directions}

The findings of multiple retrospective studies and of the prospective randomized SAPIT and trial provide compelling evidence that initiation of HAART should not be delayed pending completion of TB treatment for HIV/TB-coinfected individuals. The most recent WHO guidelines for antiretroviral therapy in adolescents and adults recommend the 
initiation of HAART between 2 and 8 weeks subsequent to the initiation of TB therapy for severely immunosuppressed coinfected individuals, as defined by a CD4 count $<200 \mathrm{~mm}^{3}$ [62]. The preliminary reported findings from the CAMELIA trial provide evidence that coinfected individuals with CD4 counts $<200 \mathrm{~mm}^{3}$ would benefit from HAART initiation early during this intensive phase of TB treatment, that is at 2 weeks as opposed to deferral of HAART to 8 weeks afterinitiation of TB therapy [59]. Further multicountry data on the timing of HAART for coinfected individuals with CD4 counts $<200 \mathrm{~mm}^{3}$ is likely to be provided by the recently concluded ACTG A5221 study [61].

An increased risk of IRIS was observed in the integrated arm of the SAPIT trial (12\% in the integrated arm versus $3.8 \%$ in sequential arm) as well as in the early arm of the CAMELIA trial (4.03 per 100 person months in the early arm versus 1.44 per 100 person months in the late arm), consistent with the findings of previous studies regarding the development of IRIS relative to HAART initiation [63-66]. However, the lack of mortality or changes in antiretroviral regimen attributable to IRIS in the SAPIT trial, coupled with the findings of a prior modeling study demonstrating the benefit of early HAART initiation in the setting of low mortality rates from TB-IRIS [67], provides further support for early HAART initiation in persons with HIVassociated TB. Although guidelines have been developed specifically for resource-limited settings [68], the ability to detect and appropriately treat IRIS in a timely fashion outside a controlled study environment requires further study.

The risk of IRIS may vary depending on the type of opportunistic pathogen in a site-specific manner. This concept may be of particular clinical relevance for central nervous system (CNS) infections. CNS-IRIS occurs after HAART initiation in approximately $1 \%$ of cases [69]. Immune restoration in the setting of CNS opportunistic infections can lead to increased intracranial pressure as a result of the inflammatory response in a relatively closed space, with potentially irreversible neurologic sequelae [70, 71]. High mortality rates have been reported in cases of CNS IRIS, including up to $57 \%$ for such pathogens as Cryptococcus neoformans [72, 73]. A recent study showed increased mortality with early initiation of HAART in the setting of concomitant HIV/cryptococcal meningitis [74]. Extrapulmonary TB, including CNS disease (manifesting as tuberculous meningitis or CNS tuberculoma), may demonstrate a different clinical course relative to primary pulmonary disease post-HAART initiation [43, 45, 74-77]. It should be noted that the great majority of patients included in the SAPIT trial had exclusively pulmonary TB, not allowing conclusions to be drawn regarding the optimal timing of HAART initiation in the setting of CNS and other forms of extrapulmonary TB. Whereas a greater proportion of participants in the CAMELIA trial had extrapulmonary $\mathrm{TB}$, it is not certain whether subgroup analysis by location of involvement could be performed. However, preliminary reports of a single center randomized trial in Vietnam examining HAART initiation in patients with HIV and CNS-TB suggested no mortality difference in the group treated immediately with HAART (within 7 days of TB treatment) as compared to the group in whom HAART was deferred (2 months post-randomization) [57]. However, there were higher rates of grade 4 adverse events in the immediate HAART arm, suggesting that deferral of HAART initiation to the continuation phase of TB treatment may be warranted in the setting of HIV and CNS-TB coinfection. The optimal timing of HAART initiation for individuals with extrapulmonary TB, as well as for those with other opportunistic infections, requires further study.

As for adults, HIV is a major risk factor for the development of pediatric TB [78]. Recommendations for deferral of HAART until after completion of TB treatment for children with mild or insignificant immunodeficiency had initially been proposed. The most recent WHO guidelines recommend initiation of HAART as soon as tuberculosis therapy is tolerated, ideally as early as 2 weeks and no later than 8 weeks subsequent to initiation of TB treatment, regardless of clinical stage and degree of immunosuppression [79]. However, studies on the optimal timing of HAART initiation among children with TB have been limited to observational reports, although a recent such study suggested a trend towards decreased mortality and higher rates of virological suppression with earlier HAART initiation in this age group [80]. Extrapolation of findings from adult studies to the pediatric population may not be possible given potential differences in pharmacokinetics and pharmacodynamics as well as challenges in definitive pediatric TB diagnosis. Further data is required to evaluate current recommendations for this specific population.

HIV patients with drug-resistant TB demonstrate reduced survival compared to those with drug-susceptible TB $[9,53,81]$. Many additional challenges exist in the comanagement of MDR-TB and XDR-TB among HIVpositive populations, including delays in the diagnosis of drug resistance, and inadequate infection control modalities, as well as the decreased efficacy, prolonged duration, and increased cost of therapeutic regimens compared to those for drug-susceptible TB [82]. Moreover, second- and thirdline $\mathrm{TB}$ regimens demonstrate their own distinct cumulative toxicities with concomitant HAART administration. For instance, the nephrotoxicity associated with tenofovir may be compounded by the antituberculous aminoglycosides and the peripheral neurotoxicity induced by stavudine and didanosine and psychiatric disturbances associated with efavirenz may be exacerbated by the antituberculous agent cycloserine. Additionally, the pill burden and gastrointestinal distress associated with drug-susceptible $\mathrm{TB}$ regimens are even greater with MDR-TB and XDR-TB regimens $[82,83]$. The timing of HAART initiation in the setting of drugresistant TB thus requires careful consideration of both the unique cumulative toxicities as well as the distinctive pharmacokinetic interactions between antiretroviral drugs and second- and third-line TB regimens [84]. Further investigation is warranted to determine if the findings of the SAPIT and CAMELIA studies are applicable to persons coinfected with HIV and drug-resistant TB. Moreover, the anticipated emergence of HIV resistance in resource-limited settings will further complicate the management of HIV/TB coinfected patients. 
Several studies have shown a benefit to initiating HAART at higher CD4 counts [85-87]. As a consequence, WHO has recently increased the recommended CD4 threshold for HAART initiation from 200 to $350 / \mathrm{mm}^{3}$ for stage 1 or 2 disease [62]. HAART initiation at even higher CD4 counts has been recommended by other groups [88]. Whereas tuberculosis is a recommended indication for initiation of HAART at any CD4 count, the WHO guidelines state that "there are limited data on the initiation of ART in patients with TB and CD4 counts of $>350$ cells $/ \mathrm{mm}^{3}$ " [62]. The SAPIT trial suggested a trend towards a mortality benefit when HAART was initiated in persons with CD4 counts of $200-500 / \mathrm{mm}^{3}$ in the integrated groups compared to the sequential group though the sample size in this subgroup was small. Although the CAMELIA trial addresses the management of HIV/TB coinfected persons with CD4 counts $<200 / \mathrm{mm}^{3}$, recommendations regarding the optimal timing of HAART for coinfected individuals with CD4 counts $>200 / \mathrm{mm}^{3}$ may not be derived from this trial or from the recently concluded ACTG A5221 study. Such a determination, with significant implications for the management of HIV/TB coinfection worldwide, awaits future study, including the results of the comparative analysis of the early and late integrated arms of the SAPIT trial.

Only approximately $42 \%$ of those in need worldwide currently receive HAART [89]. The appropriate treatment of HIV/TB-coinfected individuals has the potential to significantly reduce morbidity and mortality globally, however the ability to deliver such treatment remains a critical challenge. The available data should provide an impetus for improving access to both life-saving HIV and TB medications to all those in need of such therapy.

\section{References}

[1] UNAIDS and Joint United Nations Program on HIV/AIDS, "2008 Report on the global AIDS epidemic," http://data.unaids.org/pub/GlobalReport/2008/JC1511_GR08_ExecutiveSummary_en.pdf.

[2] World Health Organization, "Global Tuberculosis Control 2009," World Health Organization, Geneva, Switzerland, 2009, http://whqlibdoc.who.int/publications/2009/9789241563802_ eng.pdf.

[3] S. Swaminathan and B. Rekha, "Pediatric tuberculosis: global overview and challenges," Clinical Infectious Diseases, vol. 50, supplement 3, pp. S184-S194, 2010.

[4] H. Getahun, C. Gunneberg, R. Granich, and P. Nunn, "HIV infection-associated tuberculosis: the epidemiology and the response," Clinical Infectious Diseases, vol. 50, supplement 3, pp. S201-S207, 2010.

[5] E. L. Corbett, C. J. Watt, N. Walker et al., "The growing burden of tuberculosis: global trends and interactions with the HIV epidemic," Archives of Internal Medicine, vol. 163, no. 9, pp. 1009-1021, 2003.

[6] H. López-Gatell, S. R. Cole, N. A. Hessol et al., "Effect of tuberculosis on the survival of women infected with human immunodeficiency virus," American Journal of Epidemiology, vol. 165, no. 10, pp. 1134-1142, 2007.
[7] World Health Organization, "Anti-tuberculosis drug resistance in the world: fourth global report," World Health Organization, Geneva, Switzerland, 2008, http://whqlibdoc .who.int/hq/2008/WHO_HTM_TB_2008.394_eng.pdf.

[8] C. D. Wells, J. P. Cegielski, L. J. Nelson et al., "HIV infection and multidrug-resistant tuberculosis-the perfect storm," Journal of Infectious Diseases, vol. 196, supplement 1, pp. S86S107, 2007.

[9] N. R. Gandhi, A. Moll, A. W. Sturm et al., "Extensively drug-resistant tuberculosis as a cause of death in patients coinfected with tuberculosis and HIV in a rural area of South Africa," The Lancet, vol. 368, no. 9547, pp. 1575-1580, 2006.

[10] A. M. Cooper, "Cell-mediated immune responses in tuberculosis," Annual Review of Immunology, vol. 27, pp. 393-422, 2009.

[11] C. V. Harding and W. H. Boom, "Regulation of antigen presentation by Mycobacterium tuberculosis: a role for Tolllike receptors," Nature Reviews Microbiology, vol. 8, no. 4, pp. 296-307, 2010.

[12] S. K. Sharma, A. Mohan, A. Sharma, and D. K. Mitra, "Miliary tuberculosis: new insights into an old disease," The Lancet Infectious Diseases, vol. 5, no. 7, pp. 415-430, 2005.

[13] P. A. Selwyn, D. Hartel, V. A. Lewis et al., "A prospective study of the risk of tuberculosis among intravenous drug users with human immunodeficiency virus infection," The New England Journal of Medicine, vol. 320, no. 9, pp. 545-550, 1989.

[14] G. Antonucci, E. Girardi, M. C. Raviglione, and G. Ippolito, "Risk factors for tuberculosis in HIV-infected persons: a prospective cohort study," Journal of the American Medical Association, vol. 274, no. 2, pp. 143-148, 1995.

[15] N. Markowitz, N. I. Hansen, P. C. Hopewell et al., "Incidence of tuberculosis in the United States among HIV-infected persons," Annals of Internal Medicine, vol. 126, no. 2, pp. 123$132,1997$.

[16] S. Moreno, J. Baraia-Etxaburu, E. Bouza et al., "Risk for developing tuberculosis among anergic patients infected with HIV," Annals of Internal Medicine, vol. 119, no. 3, pp. 194-198, 1993.

[17] H. C. Bucher, L. E. Griffith, G. H. Guyatt et al., "Isoniazid prophylaxis for tuberculosis in HIV infection: a meta-analysis of randomized controlled trials," AIDS, vol. 13, no. 4, pp. 501507, 1999.

[18] D. Wilkinson, S. B. Squire, and P. Garner, "Effect of preventive treatment for tuberculosis in adults infected with HIV: systematic review of randomised placebo controlled trials," British Medical Journal, vol. 317, no. 7159, pp. 625-629, 1998.

[19] S. Woldehanna and J. Volmink, "Treatment of latent tuberculosis infection in HIV infected persons," Cochrane Database of Systematic Reviews, no. 1, Article ID CD000171, 2010.

[20] M. Badri, D. Wilson, and R. Wood, "Effect of highly active antiretroviral therapy on incidence of tuberculosis in South Africa: a cohort study," The Lancet, vol. 359, no. 9323, pp. 2059-2064, 2002.

[21] E. Girardi, C. A. Sabin, A. D. Monferte et al., "Incidence of tuberculosis among HIV-infected patients receiving highly active antiretroviral therapy in Europe and North America," Clinical Infectious Diseases, vol. 41, no. 12, pp. 1772-1782, 2005.

[22] G. Santoro-Lopes, A. M. F. De Pinho, L. H. Harrison, and M. Schechter, "Reduced risk of tuberculosis among Brazilian patients with advanced human immunodeficiency virus infection treated with highly active antiretroviral therapy," Clinical Infectious Diseases, vol. 34, no. 4, pp. 543-546, 2002. 
[23] S. D. Lawn, L. Myer, L.-G. Bekker, and R. Wood, "Burden of tuberculosis in an antiretroviral treatment programme in sub-Saharan Africa: impact on treatment outcomes and implications for tuberculosis control," AIDS, vol. 20, no. 12, pp. 1605-1612, 2006.

[24] P. C. Hopewell, M. Pai, D. Maher, M. Uplekar, and M. C. Raviglione, "International standards for Tuberculosis care," The Lancet Infectious Diseases, vol. 6, no. 11, pp. 710-725, 2006.

[25] D. W. Fitzgerald, M. Desvarieux, P. Severe, P. Joseph, W. D. Johnson Jr., and J. W. Pape, "Effect of post-treatment isoniazid on prevention of recurrent tuberculosis in HIV-1-infected individuals: a randomised trial," The Lancet, vol. 356, no. 9240, pp. 1470-1474, 2000.

[26] J. H. Perriens, M. E. St. Louis, Y. B. Mukadi et al., "Pulmonary tuberculosis in HIV-infected patients in Zaire-a controlled trial of treatment for either 6 or 12 months," The New England Journal of Medicine, vol. 332, no. 12, pp. 779-784, 1995.

[27] F. A. Khan, J. Minion, M. Pai et al., "Treatment of active tuberculosis in HIV-coinfected patients: a systematic review and meta-analysis," Clinical Infectious Diseases, vol. 50, no. 9, pp. 1288-1299, 2010.

[28] M. Lutfey, P. Della-Latta, V. Kapur et al., "Independent origin of mono-rifampin-resistant Mycobacterium tuberculosis in patients with AIDS," American Journal of Respiratory and Critical Care Medicine, vol. 153, no. 2, pp. 837-840, 1996.

[29] C. M. Nolan, D. L. Williams, M. D. Cave et al., "Evolution of rifampin resistance in human immunodeficiency virusassociated tuberculosis," American Journal of Respiratory and Critical Care Medicine, vol. 152, no. 3, pp. 1067-1071, 1995.

[30] W. J. Burman and B. E. Jones, "Treatment of HIV-related tuberculosis in the era of effective antiretroviral therapy," American Journal of Respiratory and Critical Care Medicine, vol. 164, no. 1, pp. 7-12, 2001.

[31] G. L. Dean, S. G. Edwards, N. J. Ives et al., "Treatment of tuberculosis in HIV-infected persons in the era of highly active antiretroviral therapy," AIDS, vol. 16, no. 1, pp. 75-83, 2002.

[32] T. R. Sterling, P. A. Pham, and R. E. Chaisson, "HIV infectionrelated tuberculosis: clinical manifestations and treatment," Clinical Infectious Diseases, vol. 50, supplement 3, pp. S223S230, 2010.

[33] A. Boulle, G. Van Cutsem, K. Cohen et al., "Outcomes of nevirapine- and efavirenz-based antiretroviral therapy when coadministered with rifampicin-based antitubercular therapy," Journal of the American Medical Association, vol. 300, no. 5, pp. 530-539, 2008.

[34] W. Manosuthi, S. Sungkanuparph, P. Tantanathip et al., "A randomized trial comparing plasma drug concentrations and efficacies between 2 nonnucleoside reverse-transcriptase inhibitor-based regimens in hiv-infected patients receiving rifampicin: the N2R study," Clinical Infectious Diseases, vol. 48, no. 12, pp. 1752-1759, 2009.

[35] M. A. French, "Disorders of immune reconstitution in patients with HIV infection responding to antiretroviral therapy," Current HIV/AIDS Reports, vol. 4, no. 1, pp. 16-21, 2007.

[36] G. Meintjes and L. Lynen, "Prevention and treatment of the immune reconstitution inflammatory syndrome," Current Opinion in HIV and AIDS, vol. 3, no. 4, pp. 468-476, 2008.

[37] T. Puthanakit, L. Aurpibul, P. Oberdorfer et al., "Hospitalization and mortality among HIV-infected children after receiving highly active antiretroviral therapy," Clinical Infectious Diseases, vol. 44, no. 4, pp. 599-604, 2007.
[38] P. M. Grant, L. Komarow, J. Andersen et al., "Risk factor analyses for immune reconstitution inflammatory syndrome in a randomized study of early vs. deferred ART during an opportunistic infection," PLoS ONE, vol. 5, no. 7, Article ID e11416, pp. 1-7, 2010.

[39] Y. C. Manabe, J. D. Campbell, E. Sydnor, and R. D. Moore, "Immune reconstitution inflammatory syndrome: risk factors and treatment implications," Journal of Acquired Immune Deficiency Syndromes, vol. 46, no. 4, pp. 456-462, 2007.

[40] D. M. Murdoch, W. D. F. Venter, C. Feldman, and A. Van Rie, "Incidence and risk factors for the immune reconstitution inflammatory syndrome in HIV patients in South Africa: a prospective study," AIDS, vol. 22, no. 5, pp. 601-610, 2008.

[41] S. A. Shelburne, F. Visnegarwala, J. Darcourt et al., "Incidence and risk factors for immune reconstitution inflammatory syndrome during highly active antiretroviral therapy," AIDS, vol. 19, no. 4, pp. 399-406, 2005.

[42] R. A. M. Breen, C. J. Smith, H. Bettinson et al., "Paradoxical reactions during tuberculosis treatment in patients with and without HIV co-infection," Thorax, vol. 59, no. 8, pp. 704-707, 2004.

[43] J. A. Crump, M. J. Tyrer, S. J. Lloyd-Owen, L. Y. Han, M. C. Lipman, and M. A. Johnson, "Miliary tuberculosis with paradoxical expansion of intracranial tuberculomas complicating human immunodeficiency virus infection in a patient receiving highly active antiretroviral therapy," Clinical Infectious Diseases, vol. 26, no. 4, pp. 1008-1009, 1998.

[44] C.-C. Hung, M.-Y. Chen, C.-F. Hsiao, S.-M. Hsieh, W.-H. Sheng, and S.-C. Chang, "Improved outcomes of HIV-1infected adults with tuberculosis in the era of highly active antiretroviral therapy," AIDS, vol. 17, no. 18, pp. 2615-2622, 2003.

[45] S. D. Lawn, L.-G. Bekker, and R. F. Miller, "Immune reconstitution disease associated with mycobacterial infections in HIV-infected individuals receiving antiretrovirals," The Lancet Infectious Diseases, vol. 5, no. 6, pp. 361-373, 2005.

[46] G. Meintjes, H. Rabie, R. J. Wilkinson, and M. F. Cotton, "Tuberculosis-associated immune reconstitution inflammatory syndrome and unmasking of tuberculosis by antiretroviral therapy," Clinics in Chest Medicine, vol. 30, no. 4, pp. 797$810,2009$.

[47] E. Navas, P. Martín-Dávila, L. Moreno et al., "Paradoxical reactions of tuberculosis in patients with the acquired immunodeficiency syndrome who are treated with highly active antiretroviral therapy," Archives of Internal Medicine, vol. 162, no. 1, pp. 97-99, 2002.

[48] N. Valin, J. Pacanowski, L. Denoeud et al., "Risk factors for 'unmasking immune reconstitution inflammatory syndrome' presentation of tuberculosis following combination antiretroviral therapy initiation in HIV-infected patients," AIDS, vol. 24, no. 10, pp. 1519-1525, 2010.

[49] A. R. Zolopa, J. Andersen, L. Komarow et al., "Early antiretroviral therapy reduces AIDS progression/death in individuals with acute opportunistic infections: a multicenter randomized strategy trial," PLoS ONE, vol. 4, no. 5, Article ID e5575, 2009.

[50] S. D. Lawn, A. D. Harries, X. Anglaret, L. Myer, and R. Wood, "Early mortality among adults accessing antiretroviral treatment programmes in sub-Saharan Africa," AIDS, vol. 22, no. 15, pp. 1897-1908, 2008.

[51] M. K. Leonard, N. Larsen, H. Drechsler et al., "Increased survival of persons with tuberculosis and human immunodeficiency virus infection, 1991-2000," Clinical Infectious Diseases, vol. 34, no. 7, pp. 1002-1007, 2002. 
[52] S. Sungkanuparph, W. Manosuthi, S. Kiertiburanakul, and A. Vibhagool, "Initiation of antiretroviral therapy in advanced AIDS with active tuberculosis: clinical experiences from Thailand," Journal of Infection, vol. 52, no. 3, pp. 188-194, 2006.

[53] W. Manosuthi, S. Chottanapand, S. Thongyen, A. Chaovavanich, and S. Sungkanuparph, "Survival rate and risk factors of mortality among HIV/tuberculosis- coinfected patients with and without antiretroviral therapy," Journal of Acquired Immune Deficiency Syndromes, vol. 43, no. 1, pp. 42-46, 2006.

[54] N. Sanguanwongse, K. P. Cain, P. Suriya et al., "Antiretroviral therapy for HIV-infected tuberculosis patients saves lives but needs to be used more frequently in Thailand," Journal of Acquired Immune Deficiency Syndromes, vol. 48, no. 2, pp. 181189, 2008.

[55] P. Tabarsi, A. S. Saber-Tehrani, P. Baghaei et al., "Early initiation of antiretroviral therapy results in decreased morbidity and mortality among patients with TB and HIV," Journal of the International AIDS Society, vol. 12, no. 1, p. 14, 2009.

[56] M. Velasco, V. Castilla, J. Sanz et al., "Effect of simultaneous use of highly active antiretroviral therapy on survival of HIV patients with tuberculosis," Journal of Acquired Immune Deficiency Syndromes, vol. 50, no. 2, pp. 148-152, 2009.

[57] M. E. Torok, N. T. B. Yen, T. T. H. Chau et al., "Randomised controlled trial of immediate versus deferred antiretroviral therapy in HIV-associated tuberculosis meningitis," in Proceedings of the 49th Interscience Conference on Antimicrobial Agents and Chemotherapy, San Francisco, Calif, USA, 2009.

[58] S. S. Abdool Karim, K. Naidoo, A. Grobler et al., "Timing of initiation of antiretroviral drugs during tuberculosis therapy," The New England Journal of Medicine, vol. 362, no. 8, pp. 697706, 2010.

[59] F. X. Blanc, T. Sok, and D. Laureillard, "Significant enhancement in survival with early ( 2 weeks) vs. late (8 weeks) initiation of highly active antiretroviral treatment (HAART) in severely immunosuppressed HIV-infected adults with newly diagnosed tuberculosis," in Proceedings of the 16th International AIDS Society Conference, Vienna, Austria, 2010.

[60] F.-X. Blanc, D. V. Havlir, P. C. Onyebujoh, S. Thim, A. E. Goldfeld, and J.-F. Delfraissy, "Treatment strategies for HIVinfected patients with tuberculosis: ongoing and planned clinical trials," Journal of Infectious Diseases, vol. 196, supplement 1, pp. S46-S51, 2007.

[61] ACTG A5221, "Immediate Versus Deferred Start of Anti-HIV Therapy in HIV Infected Adults Being Treated for Tuberculosis," http://clinicaltrials.gov/ct2/show/NCT00108862.

[62] World Health Organization, "Antiretroviral Therapy for HIV Infection in Adults and Adolescents: Recommendations for a Public Health Approach : 2010 Revision," World Health Organization, Geneva, Switzerland, 2010, http://whqlibdoc .who.int/publications/2010/9789241599764_eng.pdf.

[63] W. Burman, S. Weis, A. Vernon et al., "Frequency, severity and duration of immune reconstitution events in HIV-related tuberculosis," International Journal of Tuberculosis and Lung Disease, vol. 11, no. 12, pp. 1282-1289, 2007.

[64] N. Kumarasamy, S. Chaguturu, K. H. Mayer et al., "Incidence of immune reconstitution syndrome in HIV/tuberculosiscoinfected patients after initiation of generic antiretroviral therapy in India," Journal of Acquired Immune Deficiency Syndromes, vol. 37, no. 5, pp. 1574-1576, 2004.

[65] S. D. Lawn, L. Myer, L.-G. Bekker, and R. Wood, "Tuberculosis-associated immune reconstitution disease: incidence, risk factors and impact in an antiretroviral treatment service in South Africa," AIDS, vol. 21, no. 3, pp. 335-341, 2007.

[66] M. Narita, D. Ashkin, E. S. Hollender, and A. E. Pitchenik, "Paradoxical worsening of tuberculosis following antiretroviral therapy in patients with aids," American Journal of Respiratory and Critical Care Medicine, vol. 158, no. 1, pp. 157$161,1998$.

[67] J. T. Schiffer and T. R. Sterling, "Timing of antiretroviral therapy initiation in tuberculosis patients with AIDS: a decision analysis," Journal of Acquired Immune Deficiency Syndromes, vol. 44, no. 2, pp. 229-234, 2007.

[68] G. Meintjes, S. D. Lawn, F. Scano et al., "Tuberculosisassociated immune reconstitution inflammatory syndrome: case definitions for use in resource-limited settings," The Lancet Infectious Diseases, vol. 8, no. 8, pp. 516-523, 2008.

[69] J. A. McCombe, R. N. Auer, F. G. Maingat, S. Houston, M. J. Gill, and C. Power, "Neurologic immune reconstitution inflammatory syndrome in HIV/AIDS: outcome and epidemiology," Neurology, vol. 72, no. 9, pp. 835-841, 2009.

[70] T. Johnson and A. Nath, "Neurological complications of immune reconstitution in HIV-infected populations," Annals of the New York Academy of Sciences, vol. 1184, pp. 106-120, 2010.

[71] D. J. Pepper, S. Marais, G. Maartens et al., "Neurologic manifestations of paradoxical tuberculosis-associated immune reconstitution inflammatory syndrome: a case series," Clinical Infectious Diseases, vol. 48, no. 11, pp. e96-e107, 2009.

[72] A. Kambugu, D. B. Meya, J. Rhein et al., "Outcomes of cryptococcal meningitis in Uganda before and after the availability of highly active antiretroviral therapy," Clinical Infectious Diseases, vol. 46, no. 11, pp. 1694-1701, 2008.

[73] S. D. Lawn, L.-G. Bekker, L. Myer, C. Orrell, and R. Wood, "Cryptococcocal immune reconstitution disease: a major cause of early mortality in a South African antiretroviral programme," AIDS, vol. 19, no. 17, pp. 2050-2052, 2005.

[74] A. T. Makadzange, C. E. Ndhlovu, K. Takarinda et al., "Early versus delayed initiation of antiretroviral therapy for concurrent HIV infection and cryptococcal meningitis in subsaharan Africa," Clinical Infectious Diseases, vol. 50, no. 11, pp. 1532-1538, 2010.

[75] J. Dautremer, J. Pacanowski, P.-M. Girard, V. Lalande, F. Sivignon, and J.-L. Meynard, "A new presentation of immune reconstitution inflammatory syndrome followed by a severe paradoxical reaction in an HIV-1-infected patient with tuberculous meningitis," AIDS, vol. 21, no. 3, pp. 381-382, 2007.

[76] C.-H. Lee, C.-C. Lui, and J.-W. Liu, "Immune reconstitution syndrome in a patient with AIDS with paradoxically deteriorating brain tuberculoma," AIDS Patient Care and STDs, vol. 21, no. 4, pp. 234-239, 2007.

[77] K. Ramdas and G. Y. Minamoto, "Paradoxical presentation of intracranial tuberculomas after chemotherapy in a patient with AIDS," Clinical Infectious Diseases, vol. 19, no. 4, pp. 793794, 1994.

[78] S. M. Newton, A. J. Brent, S. Anderson, E. Whittaker, and B. Kampmann, "Paediatric tuberculosis," The Lancet Infectious Diseases, vol. 8, no. 8, pp. 498-510, 2008.

[79] World Health Organization, "Antiretroviral Therapy of HIV Infection in Infants and Children : Towards Universal Access - Recommendations for a Public Health Approach: 2010 Revision," World Health Organization, Geneva, Switzerland, 2010, http://whqlibdoc.who.int/publications/2010/9789241599801_eng.pdf. 
[80] M. Yotebieng, A. Van Rie, H. Moultrie et al., "Effect on mortality and virological response of delaying antiretroviral therapy initiation in children receiving tuberculosis treatment," AIDS, vol. 24, no. 9, pp. 1341-1349, 2010.

[81] S. Sungkanuparph, B. Eampokalap, S. Chottanapund, S. Thongyen, and W. Manosuthi, "Impact of drug-resistant tuberculosis on the survival of HIV-infected patients," International Journal of Tuberculosis and Lung Disease, vol. 11, no. 3, pp. 325-330, 2007.

[82] S. Shenoi, S. Heysell, A. Moll, and G. Friedland, "Multidrugresistant and extensively drug-resistant tuberculosis: consequences for the global HIV community," Current Opinion in Infectious Diseases, vol. 22, no. 1, pp. 11-17, 2009.

[83] G. B. Migliori, K. Dheda, R. Centis et al., "Review of multidrug-resistant and extensively drug-resistant TB: global perspectives with a focus on sub-Saharan Africa," Tropical Medicine and International Health, vol. 15, no. 9, pp. 1052 1066, 2010.

[84] S. Bonora and G. Di Perri, "Interactions between antiretroviral agents and those used to treat tuberculosis," Current Opinion in HIV and AIDS, vol. 3, no. 3, pp. 306-312, 2008.

[85] M. M. Kitahata, S. J. Gange, A. G. Abraham et al., "Effect of early versus deferred antiretroviral therapy for HIV on survival," The New England Journal of Medicine, vol. 360, no. 18, pp. 1815-1826, 2009.

[86] J. A. Sterne, M. May, D. Costagliola et al., "Timing of initiation of antiretroviral therapy in AIDS-free HIV-1-infected patients: a collaborative analysis of 18 HIV cohort studies," The Lancet, vol. 373, no. 9672, pp. 1352-1363, 2009.

[87] R. P. Walensky, L. L. Wolf, R. Wood et al., "When to start antiretroviral therapy in resource-limited settings," Annals of Internal Medicine, vol. 151, no. 3, pp. 157-166, 2009.

[88] M. A. Thompson, J. A. Aberg, P. Cahn et al., "Antiretroviral treatment of adult HIV infection: 2010 recommendations of the International AIDS Society-USA panel," Journal of the American Medical Association, vol. 304, no. 3, pp. 321-333, 2010.

[89] World Health Organization, "Towards universal access: scaling up priority HIV/AIDS interventions in the health sector," World Health Organization, Geneva, Switzerland, 2008, http://www.who.int/hiv/pub/tuapr_2009_en.pdf. 


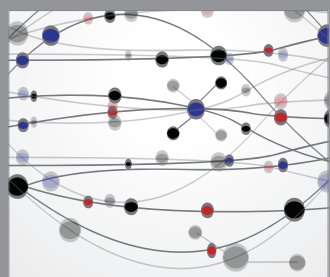

The Scientific World Journal
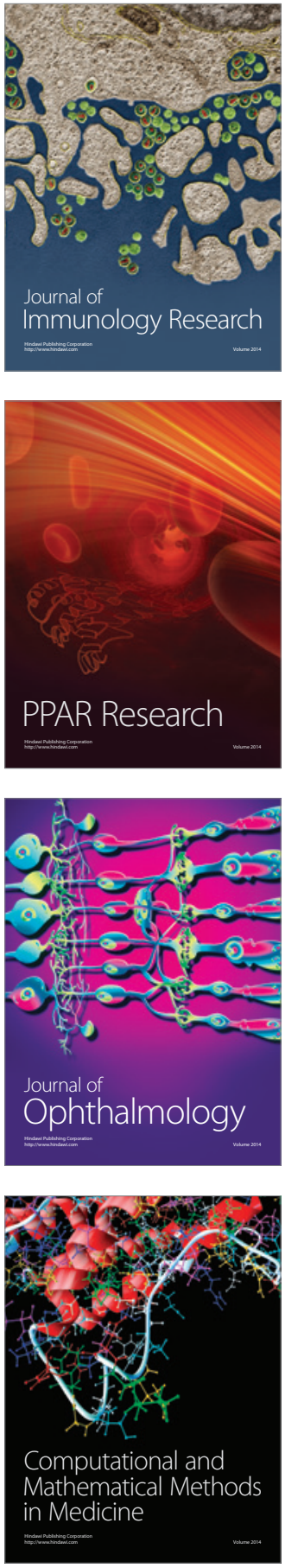

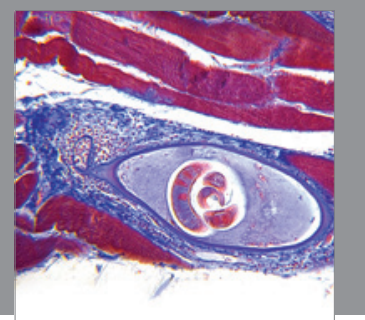

Gastroenterology

Research and Practice
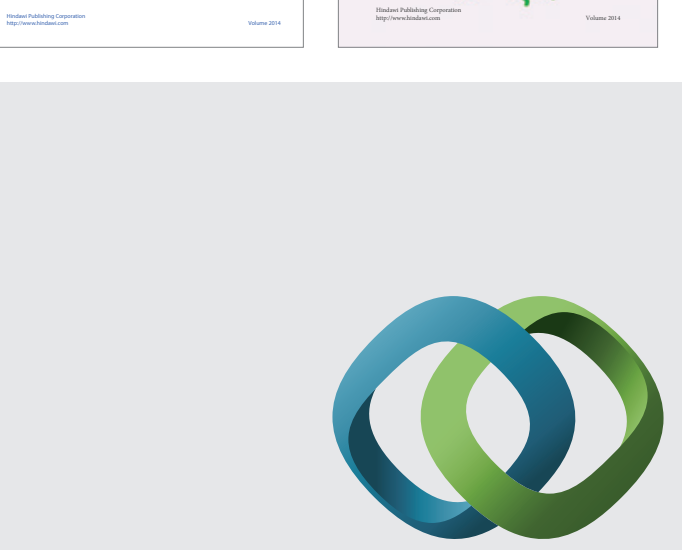

\section{Hindawi}

Submit your manuscripts at

http://www.hindawi.com
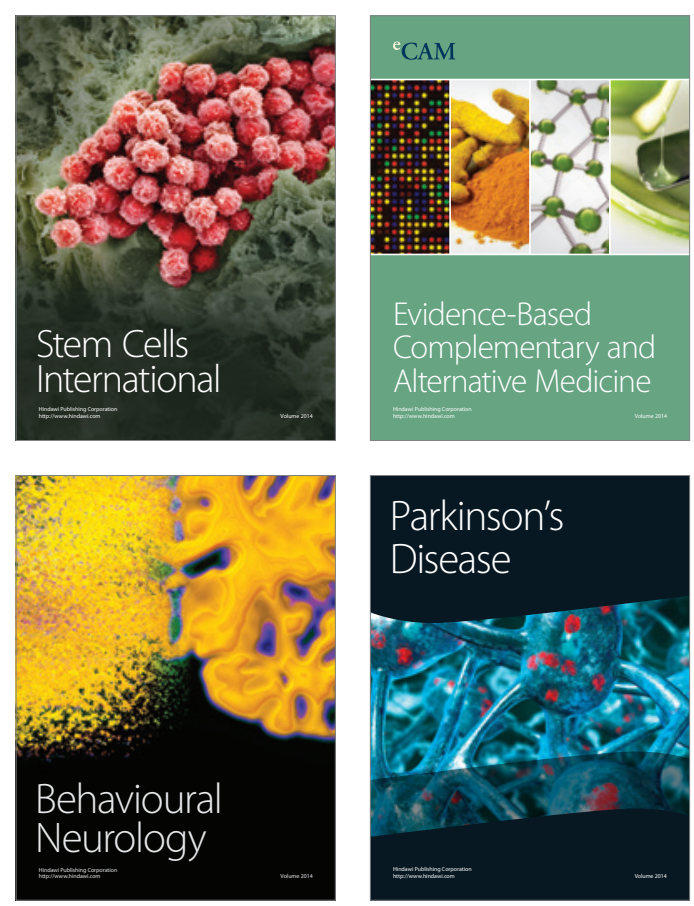

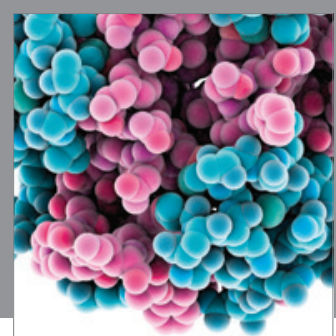

Journal of
Diabetes Research

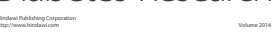

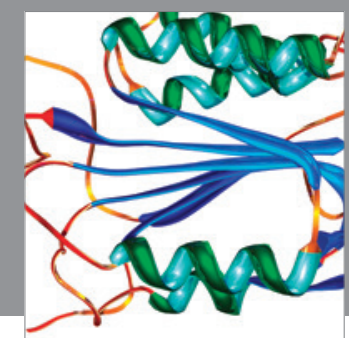

Disease Markers
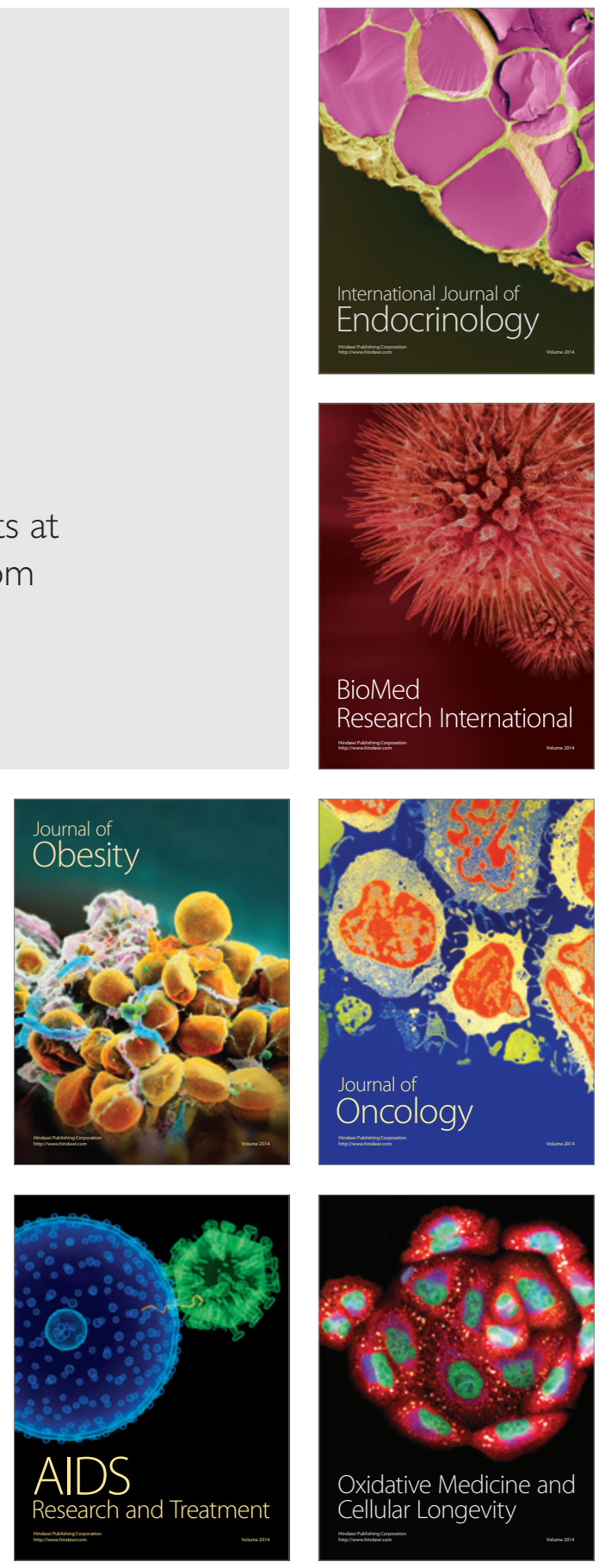